\title{
An extract of chokeberry attenuates weight gain and modulates insulin, adipogenic and inflammatory signalling pathways in epididymal adipose tissue of rats fed a fructose-rich diet
}

\author{
Bolin Qin $^{1,2 *}$ and Richard A. Anderson ${ }^{1}$ \\ ${ }^{1}$ US Department of Agriculture, Agricultural Research Service, Beltsville Human Nutrition Research Center, Diet, Genomics, \\ and Immunology Laboratory, Building 307C, Room 215, 10300 Baltimore Avenue, Beltsville, MD 20705, USA \\ ${ }^{2}$ Integrity Nutraceuticals International, 3005 Parkfield Loop, South Spring Hill, TN 37174, USA \\ (Submitted 24 February 2011 - Final revision received 10 August 2011 - Accepted 8 October 2011 - First published online 6 December 2011)
}

\section{Abstract}

Chokeberries are a rich source of anthocyanins, which may contribute to the prevention of obesity and the metabolic syndrome. The aim of the present study was to determine if an extract from chokeberries would reduce weight gain in rats fed a fructose-rich diet (FRD) and to explore the potential mechanisms related to insulin signalling, adipogenesis and inflammatory-related pathways. Wistar rats were fed a FRD for 6 weeks to induce insulin resistance, with or without chokeberry extract (CBE) added to the drinking-water (100 and $200 \mathrm{mg} / \mathrm{kg}$ body weight, daily: CBE100 and CBE200). Both doses of CBE consumption lowered epididymal fat, blood glucose, TAG, cholesterol and LDL-cholesterol. CBE consumption also elevated plasma adiponectin levels and inhibited plasma TNF- $\alpha$ and IL6, compared with the control group. There were increases in the mRNA expression for Irs1, Irs2, Pi3k, Glut1, Glut4 and Gys1, and decreases in mRNA levels

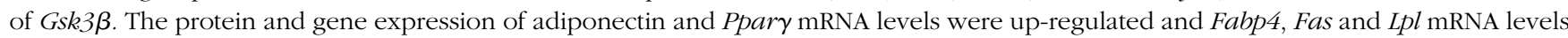
were inhibited. The levels of gene expression of inflammatory cytokines, such as $I l 1 \beta, I l 6$ and Tnf $\alpha$ were lowered, and protein and gene expression of ZFP36 (zinc finger protein) were enhanced in the epididymal adipose tissue of the rats that consumed the CBE200 extract. In summary, these results suggest that the CBE decreased risk factors related to insulin resistance by modulating multiple pathways associated with insulin signalling, adipogenesis and inflammation.

Key words: Chokeberry extract: Insulin signalling: Adipogenesis: Inflammation

Chokeberry, known as Aronia melanocarpa, is found in the eastern parts of North America, as well as Northern and Eastern Europe. Although usually consumed as a fruit, it has also been used in traditional medicine to treat hypertension and atherosclerosis in Russia and Eastern European countries $^{(1)}$. Chokeberry has attracted scientific interest because of its high content of phenolic phytochemicals. The active compounds found in chokeberry include anthocyanins and flavonoids, some at concentrations over five times greater than those found in cranberries ${ }^{(2,3)}$. A comparative in vitro study has shown that chokeberries display higher antioxidant activity with the oxygen radical absorption capacity assay than that obtained with blueberries, cranberries or lingonberries ${ }^{(4)}$.

Anthocyanins and anthocyanin-rich extracts exhibit diverse potential health benefits in animal and human studies, including cardioprotective ${ }^{(5)}$, anti-diabetic ${ }^{(6,7)}$ and anti-inflammatory properties ${ }^{(8)}$. Although it has been reported that anthocyanins are poorly absorbed and circulate in the blood exclusively as unmetabolised parent glycosides ${ }^{(9)}$, Kay et al. ${ }^{(10)}$ observed that in human subjects, anthocyanins exist in the circulation primarily as metabolites, and cyanidin 3-glycosides are absorbed and transported in human serum and urine primarily as glucuronide and methyl glucuronide derivatives. Moreover, recent studies in rodents have shown that anthocyanins are rapidly absorbed from both the stomach and small intestine ${ }^{(11)}$, with derivatives found in multiple organs, including adipose tissue $^{(12)}$.

Adipocyte and adipose tissue dysfunction are primary defects in obesity and may link obesity to several health problems, including increased risk of type 2 diabetes, hypertension, dyslipidaemia and atherosclerosis ${ }^{(13,14)}$. In cultured adipocytes, anthocyanins enhance adiponectin secretion ${ }^{(15)}$,

\footnotetext{
Abbreviations: CBE, chokeberry extract; CBE100, group fed chokeberry extract at $100 \mathrm{mg} / \mathrm{kg}$ body weight daily added to drinking water; CBE200, group fed chokeberry extract at $200 \mathrm{mg} / \mathrm{kg}$ body weight daily added to drinking water; CON, group fed with water alone; EAT, epididymal adipose tissues; FABP4, fatty acid-binding protein 4; FAS, fatty acid synthase; FRD, fructose-rich diet; Irs, insulin receptor substrate; LPL, lipoprotein lipase; ZFP36, zinc protein finger 36.
} 
regulate the expression of multiple adipocyte-specific genes $^{(15,16)}$ and also reverse TNF- $\alpha$-induced insulin resistance $^{(17)}$. In addition, dietary anthocyanins were shown to suppress obesity when administered to mice fed high-fat $\operatorname{diets}^{(18,19)}$

The aim of the present study was to investigate whether feeding an extract of chokeberry improved metabolic parameters in rats fed a fructose-rich diet (FRD) to induce insulin resistance. Effects on body weight gain and epididymal fat accumulation and the underlying molecular mechanisms of action on the expression of the adipose genes involved in insulin signalling, adipogenic and inflammation pathways were evaluated.

\section{Materials and methods}

According to the manufacturer, the chokeberry extract (CBE) used was prepared from frozen Aronia berries from Northern Europe. Berries were stirred at room temperature with 4-fold excess by weight of $60 \%$ ethanol-water for 3-4h. The mixture was then centrifuged and the supernatant was spraydried (CellBerry ${ }^{\circledR}$, the dried CBE, was provided by Integrity Nutraceuticals International (Spring Hill, TN, USA)). This extract contained at least $10 \%$ anthocyanins based on HPLC and MS analyses (lot no. TGB-071020).

\section{Animals}

Male Wistar rats ( 5 weeks old) were housed in a temperaturecontrolled room according to the Guidelines for Animal Care of the Beltsville Area Animal Care and Use Committee. After a 1-week acclimatisation period, rats were assigned randomly to receive either the $\mathrm{CBE}$ at 100 or $200 \mathrm{mg} / \mathrm{kg}$ body weight/d ( $n$ for each group: CBE100 and CBE200) added to drinking-water or water alone (CON) group. All rats were placed on a FRD for 6 weeks. The diet contained (g/kg diet): casein, 207; DL-methionine, 3.0; fructose, 600; lard, 50; cellulose, 79.8; AIN mineral mix, 50.0; zinc carbonate, 0.04; AIN vitamin mix 10.0; and green food colour $0 \cdot 15$ (89 247-Teklad Animal Diets, Madison, WI, USA). During the experimental period, the consumption of food and fluid and body weight were monitored every other day. At the termination of the feeding experiment, following an overnight fast, blood glucose levels were tested from blood collected from the tail vein. Rats were then anaesthetised and blood was collected from the portal vein in pre-cooled tubes containing EDTA and centrifuged at $5000 \mathrm{rpm}$ for $15 \mathrm{~min}$ at $4^{\circ} \mathrm{C}$. The epididymal adipose tissues (EAT) were carefully removed and weighed before being snap-frozen in liquid $\mathrm{N}_{2}$ and stored at $-80^{\circ} \mathrm{C}$ until analysed.

\section{Immunoblotting}

For the immunoanalysis of adipose tissue, approximately $100 \mathrm{mg}$ of EAT were homogenised at $4^{\circ} \mathrm{C}$ for $30 \mathrm{~s}$ in lysis buffer containing $20 \mathrm{~mm}$-Tris ( $\mathrm{pH} 7 \cdot 4$ ), 2 mm-EDTA, $50 \mathrm{~mm}-\mathrm{NaF}$, $200 \mu \mathrm{m}-\mathrm{Na}_{3} \mathrm{VO}_{4}, 250 \mu \mathrm{m}$-phenylmethylsulfonyl fluoride, $1 \mu \mathrm{M}$-leupeptin, $1 \mu \mathrm{m}$-pepstatin and $0.36 \mu \mathrm{m}$-aprotinin. Protein concentrations were determined by a commercial assay (Bio-Rad $D_{c}$ protein assay; Bio-Rad Laboratories, Hercules, CA, USA) using bovine serum albumin as a standard. Rabbit polyclonal antibody against adiponectin was purchased from ProSci (Poway, CA, USA). Rabbit polyclonal antibody against zinc finger protein 36 (ZFP36) was purchased from Genway (San Diego, CA, USA).

\section{Gene expression in epididymal adipose tissues}

Total RNA was isolated from EAT using Trizol reagent (Invitrogen, Carlsbad, CA, USA). RNA concentrations and integrity were determined using RNA 6000 Nano Assay Kit and the Bioanalyzer 2100, according to the manufacturer's instructions (Agilent, Santa Clara, CA, USA). The complementary DNA were synthesised from total RNA using SuperScript II RT (Invitrogen). The primers used are described in our previous study $^{(20)}$ and included in Table 1 . Real-time quantitative PCR was performed using SYBR Green PCR Master Mix (ABI, Forster, CA, USA). The expression of the housekeeping gene, peptidylprolyl isomerase A, was used to normalise the expression of target genes.

\section{Biochemistry}

Plasma adiponectin was determined with a rat ultrasensitive EIA (Phoenix Pharm, Burlingame, CA, USA). Plasma NEFA were measured using a colorimetric assay (Wako, Richmond, VA, USA). Serum TNF- $\alpha$ and IL- 6 were determined with a rat ultrasensitive EIA (Alpco, Salem, NH, USA). Measurement of blood glucose, insulin, TAG and cholesterol were performed as described ${ }^{(20,21)}$.

\section{Statistical analyses}

Data were analysed by one-way ANOVA followed by the least square difference (LSD) test. $P$ values $<0.05$ were considered significant.

Table 1. Real-time PCR primers

\begin{tabular}{lll}
\hline Gene & Sequence $\left(5^{\prime}\right.$ to $3^{\prime}$ forward $)$ & Sequence $\left(5^{\prime}\right.$ to $3^{\prime}$ reverse $)$ \\
\hline AdipoQ & AGGAACTTGTGCAGGTTGGA & GAACACCTGCGTCTCCCTTCT \\
Lpl & TGGAGCCCATGCTGCTG & CAAGCCAGTAATTCTATTGACCTTCTT \\
Fas & GCCTCACTCCGAGGAACAAACA & CCCGGCATTCAGAATAGTGGCA \\
Fabp4 & GAAGTGGGAGTGGGCTTT & TTATGGTGCTCTTGACTTTCCT \\
\hline
\end{tabular}

AdipoQ, adiponectin; $L p l$, lipoprotein lipase; Fas, fatty acid synthase; Fabp4, fatty acid-binding protein 4. 
Table 2. Effects of chokeberry extract (CBE) on body weight and epididymal pad weight

(Mean values with their standard errors for six rats)

\begin{tabular}{|c|c|c|c|c|c|c|}
\hline & \multicolumn{2}{|c|}{ CON } & \multicolumn{2}{|c|}{ CBE100 } & \multicolumn{2}{|c|}{ CBE200 } \\
\hline & Mean & SE & Mean & SE & Mean & SE \\
\hline Initial body weight (g) & $181^{\mathrm{a}}$ & 3 & $183^{\mathrm{a}}$ & 2 & $180^{\mathrm{a}}$ & 1 \\
\hline Final body weight (g) & $416^{\mathrm{a}}$ & 6 & $402^{\mathrm{a}}$ & 5 & $398^{\mathrm{a}}$ & 5 \\
\hline Body weight gain $(\mathrm{g})$ & $236^{\mathrm{a}}$ & 5 & $219^{b}$ & 5 & $217^{\mathrm{b}}$ & 4 \\
\hline Epididymal adipose weight (g) & $9 \cdot 2^{a}$ & 0.2 & $8 \cdot 3^{\mathrm{b}}$ & 0.2 & $8.0^{\mathrm{a}}$ & 0.2 \\
\hline
\end{tabular}

CON, group fed with water alone; CBE100, group fed CBE at $100 \mathrm{mg} / \mathrm{kg}$ body weight daily added to drinking water; CBE200, group fed CBE at $200 \mathrm{mg} / \mathrm{kg}$ body weight daily added to drinking water.

${ }^{a, b}$ Mean values within a row with unlike superscript letters were significantly different $(P<0.05)$.

\section{Results}

\section{General observations and plasma biochemistry}

Food intake and water consumed did not differ among the three groups. Body weight gain and epididymal adipose weight were reduced at both levels of CBE intake (Table 2, $P<0 \cdot 05)$. Fasting blood glucose and plasma insulin, TAG, total cholesterol, LDL-cholesterol and plasma NEFA levels were all reduced in animals consuming both levels of CBE. CBE consumption increased the plasma adiponectin and HDL-cholesterol levels (Table 3). In addition, a significant reduction in the plasma IL- 6 and TNF- $\alpha$ occurred in both the CBE groups (Table 3).

\section{Chokeberry extract altered mRNA expression in the insulin} signalling pathway and glucose uptake in epididymal adipose tissues

As shown in Fig. 1(a), CBE consumption (CBE200) with the FRD enhanced mRNA levels of components of the insulin signalling pathway, including increases in mRNA levels of insulin receptor substrate 1 (Irs1) (2.3-fold), Irs2 (1.8-fold) and phosphatidylinositol 3 kinase regulatory subunit 1 (Pi3kr1) (1.5-fold), and inhibited phosphatase and tensin homolog (Pten) mRNA levels (0.61-fold), compared with the FRD-fed control rats.

As shown in Fig. 1(b), CBE consumption (CBE200) induced an increase in Glut1 (1.6-fold), Glut4 (1.5-fold) and glycogen synthase (Gys) (1.5-fold) mRNA expression, and inhibited glycogen synthase kinase $3 \beta$ (Gsk3 $\beta$ ) mRNA levels (0.62-fold), compared with the FRD-fed control rats. Similar trends were observed in the CBE100 group but values were not significant (data not shown).

\section{Consumption of chokeberry extract modulated the} expression of genes and proteins involved in epididymal adipose adipogenesis

As shown in Fig. 2(a) and (b), CBE consumption (CBE200) caused a significant increase in adiponectin (AdipoQ) mRNA levels (2·1-fold) and adiponectin protein levels (169\%), compared with the FRD-fed control rats $(P<0.05$, both). CBE also induced Ppar $\gamma$ mRNA expression (1.6-fold) and inhibited fatty acid binding protein 4 (Fabp4) (0.7-fold), fatty acid synthase (Fas) (0.63-fold) and Lpl (0.65-fold) mRNA expression (Fig. 2(c)), but did not significantly affect fatty acid translocase (Cd36) mRNA expression. Changes in the CBE100 group were not significant (data not shown).

\section{Chokeberry extract inhibited the epididymal adipose inflammation gene expression and induced ZFP36 expression}

As shown in Fig. 3(a), CBE consumption (CBE200) caused a significant decrease in $\operatorname{Tnf} \alpha$ (0.52-fold), Il $\beta$ (0.38-fold) and $I l 6(0 \cdot 45$-fold $)$ mRNA levels, compared with the FRD-fed

Table 3. Effects of chokeberry extract (CBE) on blood and plasma parameters in the fasted state (Mean values with their standard errors for six rats)

\begin{tabular}{|c|c|c|c|c|c|c|}
\hline & \multicolumn{2}{|c|}{ CON } & \multicolumn{2}{|c|}{ CBE100 } & \multicolumn{2}{|c|}{ CBE200 } \\
\hline & Mean & $\mathrm{SE}$ & Mean & SE & Mean & SE \\
\hline Blood glucose $(\mathrm{mmol} / \mathrm{l})$ & $4.9^{a}$ & 0.2 & $4 \cdot 4^{\mathrm{b}}$ & 0.2 & $4 \cdot 3^{\mathrm{b}}$ & 0.3 \\
\hline Insulin (ng/ml) & $1 \cdot 3^{\mathrm{a}}$ & 0.12 & $0.95^{\mathrm{b}}$ & 0.06 & $0.91^{\mathrm{b}}$ & 0.09 \\
\hline $\mathrm{TAG}(\mathrm{mmol} / \mathrm{l})$ & $1.92^{\mathrm{a}}$ & 0.15 & $1.25^{\mathrm{b}}$ & 0.11 & $1.15^{\mathrm{b}}$ & 0.13 \\
\hline Cholesterol $(\mathrm{mmol} / \mathrm{l})$ & $2.35^{\mathrm{a}}$ & 0.19 & $1.65^{\mathrm{b}}$ & 0.18 & $1.58^{\mathrm{b}}$ & 0.14 \\
\hline LDL-C $(\mathrm{mmol} / \mathrm{l})$ & $1.18^{\mathrm{a}}$ & 0.13 & $0.83^{\mathrm{b}}$ & 0.13 & $0.75^{\mathrm{b}}$ & 0.13 \\
\hline $\mathrm{HDL}-\mathrm{C}(\mathrm{mmol} / \mathrm{l})$ & $0.46^{\mathrm{a}}$ & 0.03 & $0.62^{\mathrm{b}}$ & 0.04 & $0.70^{\mathrm{b}}$ & 0.02 \\
\hline $\mathrm{NEFA}(\mathrm{mmol} / \mathrm{l})$ & $0.75^{\mathrm{a}}$ & 0.07 & $0.48^{\mathrm{b}}$ & 0.03 & $0.43^{\mathrm{b}}$ & 0.05 \\
\hline Adiponectin $(\mu \mathrm{g} / \mathrm{ml})$ & $19 \cdot 8^{\mathrm{a}}$ & $2 \cdot 1$ & $27 \cdot 3^{b}$ & 2.4 & $29.8^{\mathrm{b}}$ & 2.6 \\
\hline IL-6 (pg/ml) & $220^{a}$ & 10 & $158^{\mathrm{b}}$ & 7 & $81^{\mathrm{c}}$ & 5 \\
\hline TNF- $\alpha(\mathrm{pg} / \mathrm{ml})$ & $353^{a}$ & 9 & $190^{\mathrm{b}}$ & 10 & $103^{\mathrm{c}}$ & 6 \\
\hline
\end{tabular}

CON, group fed with water alone; CBE100, group fed $\mathrm{CBE}$ at $100 \mathrm{mg} / \mathrm{kg}$ body weight daily added to drinking water; CBE200, group fed CBE at $200 \mathrm{mg} / \mathrm{kg}$ body weight daily added to drinking water; LDL-C, LDL-cholesterol; HDL-C, HDL-cholesterol.

${ }^{a, b, c}$ Mean values within a row with unlike superscript letters were significantly different $(P<0.05)$. 

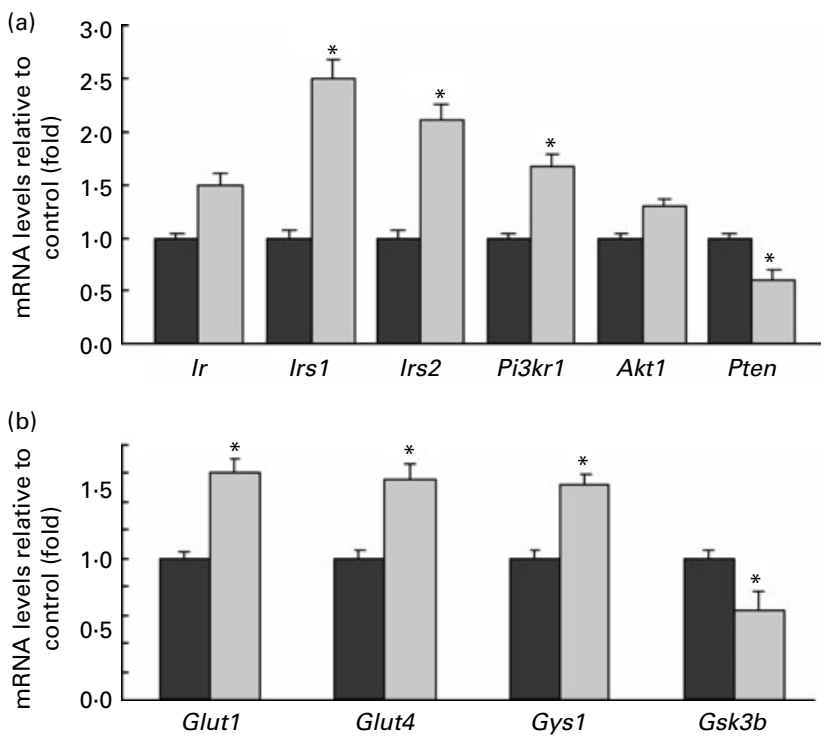

Fig. 1. Effects of feeding a chokeberry extract (CBE) on the mRNA levels related to insulin signalling, GLUT and glycogen synthesis in epididymal adipose tissue. $\square$, Control group; $\square$, group fed CBE at $200 \mathrm{mg} / \mathrm{kg}$ body weight daily (CBE200). (a) Ir, Irs1, Irs2, Pi3kr1, Akt1 and Pten and (b) Glut1, Glut4, Gys 1 and Gsk3 3 . Values are means with their standard errors and are presented as fold of control $(n 5-6)$. * Mean values were significantly different from those of the control group $(P<0.05)$.

control rats. In contrast to these inflammatory factors, CBE consumption enhanced Zfp36 mRNA and ZFP36 protein expression (Fig. 3(b) and (c), 1.45-fold and 139\%). Changes in the CBE100 group were not significant (data not shown).

\section{Discussion}

Consumption of a FRD contributes to insulin resistance, hyperinsulinaemia, dyslipidaemia and hypertension in animal models ${ }^{(22-24)}$. Furthermore, consumption of a FRD leads to abdominal adipose tissue endocrine dysfunction in normal rats, and increased adipose tissue mass and adipocyte size ${ }^{(25)}$. Growing evidence suggests that adipose tissue plays a crucial role in the regulation of systemic energy homoeostasis, insulin sensitivity and lipid/carbohydrate metabolism ${ }^{(26)}$. In the present study, we used the FRD-fed rat model to investigate the effects of a CBE rich in anthocyanins. The present data indicated that CBE consumption reduced weight gain, epididymal fat accumulation and improved systemic glucose/lipid metabolism. We also demonstrated that CBE consumption increased plasma adiponectin levels and decreased plasma TNF- $\alpha$ and IL-6 levels. In addition, we demonstrated that consumption of $\mathrm{CBE}$ regulated gene expression in multiple pathways involved in insulin signalling, adipogenesis and inflammation.

FRD-induced adipose tissue dysfunction in studies of highpolyphenol extracts of other plants caused alterations in the production of many adipocyte-derived factors such as NEFA and adiponectin ${ }^{(24)}$. These dysregulated factors induced local and systemic insulin resistance, which is a major contributor to the pathogenesis of type 2 diabetes and plays a key role in associated metabolic abnormalities, such as obesity, dyslipidaemia and hypertension ${ }^{(27)}$. Evidence from human and animal studies demonstrated that loss of body weight is associated with an increase of insulin sensitivity ${ }^{(6,28,29)}$. In the present study, we found that consumption of a CBE, high in polyphenols, reduced weight gain and epididymal fat accumulation, and improved systemic insulin sensitivityrelated factors, such as fasting glucose, plasma insulin and lipids. At the molecular level, although the FRD impaired insulin signalling pathways in multiple tissues, such as liver ${ }^{(30)}$, skeletal muscle ${ }^{(23)}$ and adipose tissue ${ }^{(24)}$, the consumption of $\mathrm{CBE}$ improved the impaired gene expression related to insulin signalling and glucose uptake in EAT, and up-regulated the decreased Irs1, Irs 2 and Pi3k mRNA expression and the expression of other genes related to carbohydrate metabolism, such as Glut1, Glut4 and Gys1. CBE also inhibited the expression of Pten and Gsk3 $\beta$ mRNA, which are increased in insulin-resistant adipose tissue ${ }^{(31,32)}$ (Fig. 1).

In contrast to many other factors derived from adipose tissue, circulating adiponectin and adipose adiponectin expression are decreased in insulin resistance ${ }^{(33,34)}$. In most clinical reports, primate studies and genetic models, serum adiponectin levels have been reported to be negatively correlated with body weight, visceral fat mass and resting insulin levels ${ }^{(35-37)}$. Transgenic mice overexpressing $A d i p o Q$ have increased insulin sensitivity and improved glucose tolerance and TAG clearance ${ }^{(38)}$. We have reported previously that FRD feeding significantly decreased plasma adiponectin and $A d i p o Q$ mRNA expression ${ }^{(24)}$. In the present study, we observed that feeding CBE significantly increased plasma adiponectin levels and the mRNA and protein expression of adipose adiponectin of FRD-fed rats (Fig. 2). These results support the previous finding in human subjects that combination therapy of statins with an extract of chokeberry
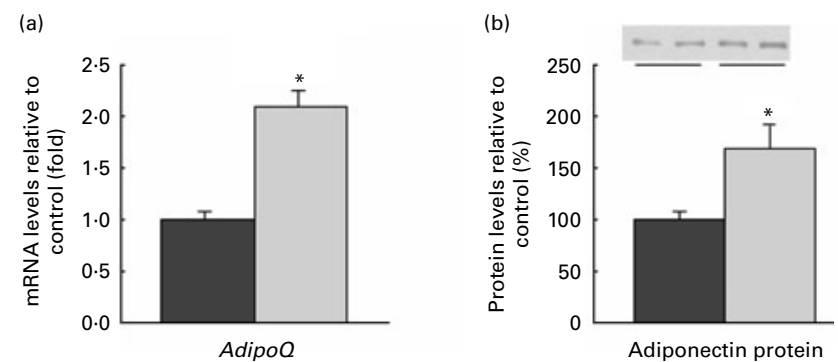

(c)

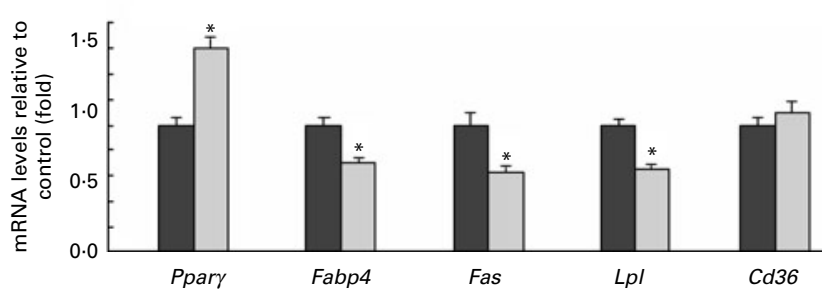

Fig. 2. Effects of feeding a chokeberry extract (CBE) on the expression of genes and proteins involved in adipogenesis in epididymal adipose tissue. $\square$, Control group; $\square$, group fed CBE at $200 \mathrm{mg} / \mathrm{kg}$ body weight daily (CBE200). (a) AdipoQ mRNA, (b) adiponectin protein and (c) Ppary mRNA, Fabp4, Fas, $L p l$ and Cd36 mRNA. (b) Representative experiments on the immunoblots of adiponectin were analysed using densitometry. Values are means with their standard errors and are presented as percentage of control $(n 5-6)$. * Mean values were significantly different from those of the control group $(P<0.05)$. 


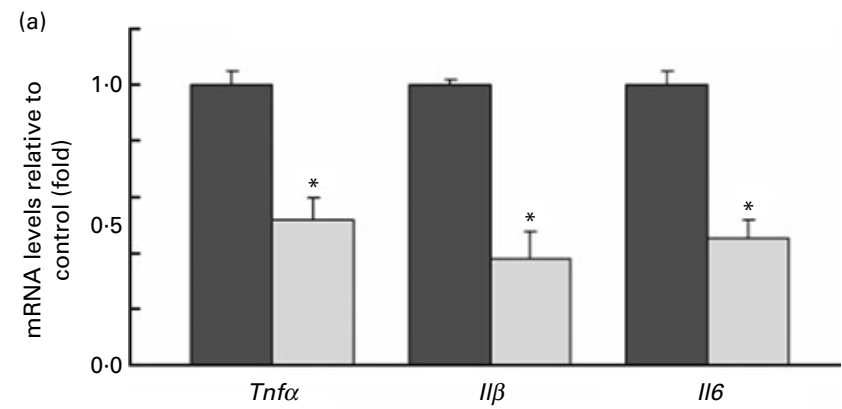

(b)

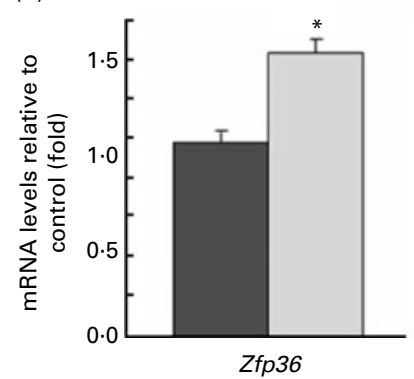

(c)

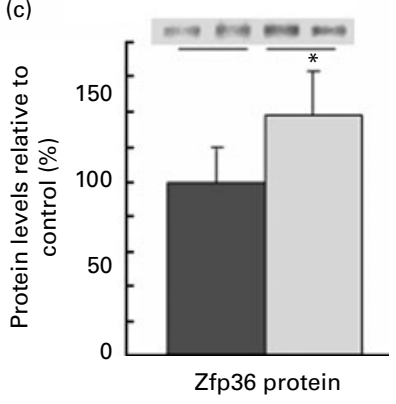

Fig. 3. Effects of feeding a chokeberry extract (CBE) on the expression of genes and proteins involved in inflammation in epididymal adipose tissue. 口, Control group; $\square$, group fed CBE at $200 \mathrm{mg} / \mathrm{kg}$ body weight daily (CBE200). (a) Tnf $\alpha, \| \beta$ and 116 mRNA, (b) Zfp36 mRNA and (c) ZFP36 protein. (c) Representative experiments on the immunoblots of ZFP36 were analysed using densitometry. Values are means with their standard errors and are presented as fold of control $(n 5-6)$. * Mean values were significantly different from those of the control group $(P<0.05)$.

increased plasma adiponectin levels in patients after myocardial infarction ${ }^{(8)}$. Adiponectin possesses insulin sensitising and anti-atherogenic properties ${ }^{(35)}$.

It is well known that increased adipose tissue mass and adipocyte dysfunction associated with obesity are linked to the abnormal regulation of adipogenesis ${ }^{(39)}$. PPAR $\gamma$, a master regulator of adipogenesis ${ }^{(40)}$, plays a critical role in glucose metabolism and energy homoeostasis ${ }^{(41,42)}$. Fructose feeding induced a lower Ppary mRNA expression in white adipose tissue, and a PPAR ligand reversed the down-regulated expression of PPAR $\gamma$ and systemic insulin resistance ${ }^{(43)}$. In the present study, we observed that CBE consumption increased Ppary mRNA expression in EAT. PPAR $\gamma$ regulates multiple genes in the adipose tissue regulating adipogenesis, including those encoding the adipocyte fatty acid-binding protein 4 (FABP4), fatty acid synthase (FAS) and lipoprotein lipase (LPL). FABP4 is postulated to be an early marker of the metabolic syndrome and the future onset of type 2 diabetes ${ }^{(44,45)}$. Fabp4-deficient mice are protected from insulin resistance, hyperglycaemia, dyslipidaemia and atherosclerosis ${ }^{(46,47)}$. We have reported that FRD feeding induced the overexpression of Fabp $4 \mathrm{mRNA}^{(24)}$. FAS is a key enzyme in de novo lipogenesis. Studies have reported that Fas mRNA and protein levels are elevated in obese Zucker rats ${ }^{(48)}$, and polyphenols from cinnamon $^{(24)}$ and dietary green tea inhibit Fas mRNA expression in diet-induced insulin-resistant animals ${ }^{(49)}$. LPL, the rate-limiting enzyme in TAG-rich lipoprotein catabolism, provides TAG-derived fatty acids to adipose tissue for storage.
Studies have shown that polyphenols from cinnamon and green tea also inhibit $L p l$ mRNA expression and other genes of lipogenesis ${ }^{(24,49)}$. In the present study, the data show that feeding polyphenols from chokeberry suppressed Fabp4, Fas and $L p l$ mRNA levels in EAT. CD36, referred to as fatty acid translocase, is a transmembrane protein present in many tissues that is believed to play a role in facilitating fatty acid transport ${ }^{(50)}$. In ob/ob mice, and FRD-fed rats, CD36 mRNA $^{(51)}$ and protein ${ }^{(24)}$ levels in the adipose tissue were increased. CBE consumption did not affect CD36 mRNA expression in the adipose tissue.

Substantial evidence indicates that a state of low-grade chronic inflammation typically is associated with obesity, and the increased production of pro-inflammatory cytokines by adipose tissue plays a crucial role in the development of insulin resistance ${ }^{(52,53)}$. FRD feeding also induces the overexpression of plasma TNF- $\alpha$ and IL- 6 , which both contribute to the development of CVD by promoting insulin resistance, dyslipidaemia and endothelial dysfunction ${ }^{(54)}$. TNF- $\alpha$ is known to be a potent negative regulator of adipogenesis and PPAR $y$ function ${ }^{(55)}$. The present results suggest that consumption of CBE not only inhibited the plasma levels of TNF- $\alpha$ and IL- 6 but also induced a decrease of mRNA expression of $\operatorname{Tnf} \alpha$ and $I l \beta$ and $I l \sigma$. This is in agreement with a human study in which chronic chokeberry consumption reduced the severity of plasma inflammation, increased anti-inflammation factor and increased plasma adiponectin levels ${ }^{(8)}$. Previous studies suggested that Zfp36, an antiinflammatory protein, increased $\operatorname{Tn} f \alpha$ mRNA degradation by binding to its $3^{\prime}$ untranslated region ${ }^{(56)}$, and that omental adipose Zfp36 mRNA levels were correlated with insulin, insulin resistance index and adiponectinaemia in women ${ }^{(57)}$. In the present study, we found that CBE consumption increased adipose Zfp36 protein and mRNA expression, which is consistent with CBE feeding-induced decreases in TNF- $\alpha$ expression and increases in adiponectin expression in plasma and adipose tissue.

In summary, the present study provides evidence that an anthocyanin-rich extract of chokeberry reduced body weight gain and abdominal fat, improved the risk factors related to the metabolic syndrome in plasma and modulated multiple signalling pathways related to adipose dysfunction in an animal model. The present findings suggest that chokeberry or its extract might be beneficial in preventing or decreasing obesity and the metabolic syndrome. Further studies are needed in human volunteers at increased risks for diet-related chronic disease to ascertain the beneficial effects from consumption of polyphenols such as those found in chokeberry.

\section{Acknowledgements}

The present study was supported in part by a USDA Cooperative Research and Development Agreement (CRADA no.583K95-7-1184) with Integrity Nutraceuticals International. The authors gratefully appreciate Marilyn M. Polansky and Dr Harry Dawson for their assistance. They would also like to thank Dr Joseph F. Urban, Jr for critically reviewing the manuscript. R. A. A. was involved with planning and 
evaluation of the study and writing of the manuscript. B. Q. was involved in all phases of the study. B. Q. is a visiting scientist, working at the USDA/ARS Beltsville Human Nutrition Research Center, and employed by Integrity Nutraceuticals International; R. A. A. has no conflicts of interest to declare. Mention of trade names or commercial products in this publication is solely for the purpose of providing specific information and does not imply recommendation or endorsement by the US Department of Agriculture. The USDA is an equal opportunity provider and employer.

\section{References}

1. Kokotkiewicz A, Jaremicz Z \& Luczkiewicz M (2010) Aronia plants: a review of traditional use, biological activities, and perspectives for modern medicine. J Med Food 13, 255-269.

2. Wu X, Gu L, Prior RL, et al. (2004) Characterization of anthocyanins and proanthocyanidins in some cultivars of Ribes, Aronia, and Sambucus and their antioxidant capacity. J Agric Food Chem 52, 7846-7856.

3. Wu X, Beecher GR, Holden JM, et al. (2006) Concentrations of anthocyanins in common foods in the United States and estimation of normal consumption. J Agric Food Chem 54, 4069-4075.

4. Zheng W \& Wang SY (2003) Oxygen radical absorbing capacity of phenolics in blueberries, cranberries, chokeberries, and lingonberries. J Agric Food Chem 51, 502-509.

5. Bell DR \& Gochenaur K (2006) Direct vasoactive and vasoprotective properties of anthocyanin-rich extracts. J Appl Physiol 100, 1164-1170.

6. Utzschneider KM, Carr DB, Barsness SM, et al. (2004) Diet-induced weight loss is associated with an improvement in beta-cell function in older men. J Clin Endocrinol Metab 89, 2704-2710.

7. Valcheva-Kuzmanova S, Kuzmanov K, Mihova V, et al. (2007) Antihyperlipidemic effect of Aronia melanocarpa fruit juice in rats fed a high-cholesterol diet. Plant Foods Hum Nutr 62, 19-24.

8. Naruszewicz M, Laniewska I, Millo B, et al. (2007) Combination therapy of statin with flavonoids rich extract from chokeberry fruits enhanced reduction in cardiovascular risk markers in patients after myocardial infarction (MI). Atherosclerosis 194, e179-e184.

9. Cao G, Muccitelli HU, Sanchez-Moreno C, et al. (2001) Anthocyanins are absorbed in glycated forms in elderly women: a pharmacokinetic study. Am J Clin Nutr 73, 920-926.

10. Kay CD, Mazza GJ \& Holub BJ (2005) Anthocyanins exist in the circulation primarily as metabolites in adult men. J Nutr 135, 2582-2588.

11. Talavera S, Felgines C, Texier O, et al. (2004) Anthocyanins are efficiently absorbed from the small intestine in rats. $J$ Nutr 134, 2275-2279.

12. Felgines C, Texier O, Garcin P, et al. (2009) Tissue distribution of anthocyanins in rats fed a blackberry anthocyanin-enriched diet. Mol Nutr Food Res 53, 1098-1103.

13. Hajer GR, van Haeften TW \& Visseren FL (2008) Adipose tissue dysfunction in obesity, diabetes, and vascular diseases. Eur Heart J 29, 2959-2971.

14. Blüher M (2009) Adipose tissue dysfunction in obesity. Exp Clin Endocrinol Diabetes 117, 241-250.

15. Tsuda T, Ueno Y, Aoki H, et al. (2004) Anthocyanin enhances adipocytokine secretion and adipocyte-specific gene expression in isolated rat adipocytes. Biochem Biophys Res Commun 316, 149-157.

16. Tsuda T, Ueno Y, Kojo H, et al. (2005) Gene expression profile of isolated rat adipocytes treated with anthocyanins. Biochim Biophys Acta 1733, 137-147.

17. Guo H, Ling W, Wang Q, et al. (2008) Cyanidin 3-glucoside protects 3T3-L1 adipocytes against $\mathrm{H}_{2} \mathrm{O}_{2^{-}}$or TNF-alphainduced insulin resistance by inhibiting c-Jun $\mathrm{NH}_{2}$-terminal kinase activation. Biochem Pharmacol 75, 1393-1401.

18. Tsuda T, Horio F, Uchida K, et al. (2003) Dietary cyanidin 3-O-beta-D-glucoside-rich purple corn color prevents obesity and ameliorates hyperglycemia in mice. $J$ Nutr $\mathbf{1 3 3}$, 2125-2130.

19. Prior RL, Wu X, Gu L, et al. (2009) Purified berry anthocyanins but not whole berries normalize lipid parameters in mice fed an obesogenic high fat diet. Mol Nutr Food Res 53, 1406-1418.

20. Qin B, Polansky MM, Harry D, et al. (2010) Green tea polyphenols improve cardiac muscle mRNA and protein levels of signal pathways related to insulin and lipid metabolism and inflammation in insulin-resistant rats. Mol Nutr Food Res $\mathbf{5 4}$, Suppl. 1, S14-S23.

21. Qin B, Anderson RA \& Adeli K (2008) Tumor necrosis factoralpha directly stimulates the overproduction of hepatic apolipoprotein B100-containing VLDL via impairment of hepatic insulin signaling. Am J Physiol Gastrointest Liver Physiol 294, G1120-G1129.

22. Elliott SS, Keim NL, Stern J, et al. (2002) Fructose, weight gain, and the insulin resistance syndrome. Am J Clin Nutr 76, 911-922.

23. Qin B, Nagasaki M, Ren M, et al. (2004) Cinnamon extract prevents the insulin resistance induced by a high-fructose diet. Horm Metab Res 36, 119-125.

24. Qin B, Polansky MM \& Anderson RA (2010) Cinnamon extract regulates plasma levels of adipose-derived factors and expression of multiple genes related to carbohydrate metabolism and lipogenesis in adipose tissue of fructosefed rats. Horm Metab Res 42, 187-193.

25. Alzamendi A, Giovambattista A, Raschia A, et al. (2009) Fructose-rich diet-induced abdominal adipose tissue endocrine dysfunction in normal male rats. Endocrine 35, 227-232.

26. Havel PJ (2004) Update on adipocyte hormones: regulation of energy balance and carbohydrate/lipid metabolism. Diabetes 53, Suppl. 1, S143-S151.

27. Guilherme A, Virbasius JV, Puri V, et al. (2008) Adipocyte dysfunctions linking obesity to insulin resistance and type 2 diabetes. Nat Rev Mol Cell Biol 9, 367-377.

28. Bogardus C, Ravussin E, Robbins DC, et al. (1984) Effects of physical training and diet therapy on carbohydrate metabolism in patients with glucose intolerance and noninsulin-dependent diabetes mellitus. Diabetes 33, 311-318.

29. Kong WH, Oh SH, Ahn YR, et al. (2008) Antiobesity effects and improvement of insulin sensitivity by 1-deoxynojirimycin in animal models. J Agric Food Chem 56, 2613-2619.

30. Taghibiglou C, Rashid-Kolvear F, van Iderstine SC, et al. (2002) Hepatic very low density lipoprotein-ApoB overproduction is associated with attenuated hepatic insulin signaling and overexpression of protein-tyrosine phosphatase $1 \mathrm{~B}$ in a fructose-fed hamster model of insulin resistance. J Biol Chem 277, 793-803.

31. Komazawa N, Matsuda M, Kondoh G, et al. (2004) Enhanced insulin sensitivity, energy expenditure and thermogenesis in adipose-specific Pten suppression in mice. Nat Med 10, 1208-1215.

32. Eldar-Finkelman $\mathrm{H}$, Schreyer SA, Shinohara MM, et al. (1999) Increased glycogen synthase kinase-3 activity in 
diabetes- and obesity-prone C57BL/6J mice. Diabetes $\mathbf{4 8}$ $1662-1666$.

33. Ukkola O \& Santaniemi M (2002) Adiponectin: a link between excess adiposity and associated comorbidities? J Mol Med 80, 696-702.

34. Hu E, Liang P \& Spiegelman BM (1996) AdipoQ is a novel adipose-specific gene dysregulated in obesity. J Biol Chem 271, 10697-10703.

35. Berg AH, Combs TP \& Scherer PE (2002) ACRP30/adiponectin: an adipokine regulating glucose and lipid metabolism. Trends Endocrinol Metab 13, 84-89.

36. Hotta K, Funahashi T, Arita Y, et al. (2000) Plasma concentrations of a novel, adipose-specific protein, adiponectin, in type 2 diabetic patients. Arterioscler Thromb Vasc Biol 20, 1595-1599.

37. Hotta K, Funahashi T, Bodkin NL, et al. (2001) Circulating concentrations of the adipocyte protein adiponectin are decreased in parallel with reduced insulin sensitivity during the progression to type 2 diabetes in rhesus monkeys. Diabetes 50, 1126-1133.

38. Combs TP, Pajvani UB, Berg AH, et al. (2004) A transgenic mouse with a deletion in the collagenous domain of adiponectin displays elevated circulating adiponectin and improved insulin sensitivity. Endocrinology 145, 367-383.

39. Rodriguez-Acebes S, Palacios N, Botella-Carretero JI, et al. (2010) Gene expression profiling of subcutaneous adipose tissue in morbid obesity using a focused microarray: distinct expression of cell-cycle- and differentiation-related genes. BMC Med Genomics 3, 61.

40. Tontonoz P, Hu E, Graves RA, et al. (1994) mPPAR gamma 2: tissue-specific regulator of an adipocyte enhancer. Genes Dev 8, 1224-1234.

41. Tontonoz P \& Spiegelman BM (2008) Fat and beyond: the diverse biology of PPARgamma. Annu Rev Biochem 77, 289-312.

42. Rosen ED \& MacDougald OA (2006) Adipocyte differentiation from the inside out. Nat Rev Mol Cell Biol 7, 885-896.

43. Shih CC, Lin CH, Lin WL, et al. (2009) Momordica charantia extract on insulin resistance and the skeletal muscle GLUT4 protein in fructose-fed rats. J Ethnopharmacol 123, 82-90.

44. Tso AW, Xu A, Sham PC, et al. (2007) Serum adipocyte fatty acid binding protein as a new biomarker predicting the development of type 2 diabetes: a 10-year prospective study in a Chinese cohort. Diabetes Care 30, 2667-2672.

45. $\mathrm{Xu} \mathrm{A}$, Tso AW, Cheung BM, et al. (2007) Circulating adipocyte-fatty acid binding protein levels predict the development of the metabolic syndrome: a 5-year prospective study. Circulation 115, 1537-1543.

46. Boord JB, Maeda K, Makowski L, et al. (2004) Combined adipocyte-macrophage fatty acid-binding protein deficiency improves metabolism, atherosclerosis, and survival in apolipoprotein E-deficient mice. Circulation 110, 1492-1498.

47. Makowski L, Boord JB, Maeda K, et al. (2001) Lack of macrophage fatty-acid-binding protein aP2 protects mice deficient in apolipoprotein E against atherosclerosis. Nat $\mathrm{Med}$ 7, $699-705$

48. Guichard C, Dugail I, Le LX, et al. (1992) Genetic regulation of fatty acid synthetase expression in adipose tissue: overtranscription of the gene in genetically obese rats. J Lipid Res 33, 679-687.

49. Lee MS, Kim CT \& Kim Y (2009) Green tea (- )-epigallocatechin3 -gallate reduces body weight with regulation of multiple genes expression in adipose tissue of diet-induced obese mice. Ann Nutr Metab 54, 151-157.

50. Ibrahimi A \& Abumrad NA (2002) Role of CD36 in membrane transport of long chain fatty acids. Curr Opin Clin Nutr Metab Care 5, 139-145.

51. Memon RA, Fuller J, Moser A, et al. (1999) Regulation of putative fatty acid transporters and acyl-CoA synthetase in liver and adipose tissue in ob/ob mice. Diabetes $\mathbf{4 8}$, $121-127$

52. Hotamisligil GS (2003) Inflammatory pathways and insulin action. Int J Obes Relat Metab Disord 27, Suppl. 3, S53-S55.

53. Schenk S, Saberi M \& Olefsky JM (2008) Insulin sensitivity: modulation by nutrients and inflammation. J Clin Invest 118, 2992-3002.

54. Wilson PW (2008) Evidence of systemic inflammation and estimation of coronary artery disease risk: a population perspective. Am J Med 121, S15-S20.

55. Zhang B, Berger J, Hu E, et al. (1996) Negative regulation of peroxisome proliferator-activated receptor-gamma gene expression contributes to the antiadipogenic effects of tumor necrosis factor-alpha. Mol Endocrinol 10, 1457-1466.

56. Carballo E, Lai WS \& Blackshear PJ (1998) Feedback inhibition of macrophage tumor necrosis factor-alpha production by tristetraprolin. Science 281, 1001-1005.

57. Bouchard L, Vohl MC, Deshaies Y, et al. (2007) Visceral adipose tissue zinc finger protein 36 mRNA levels are correlated with insulin, insulin resistance index, and adiponectinemia in women. Eur J Endocrinol 157, 451-457. 